\title{
The effect of corrective exercises on the thoracic kyphosis and lumbar lordosis of boy students
}

\author{
Ahmet Gokhan YAZICI, Mohsen MOHAMMADI \\ Department of Physical Education \& Sport, Atatürk University, Turkey. \\ Address correcpondence to A. G. Yazici, e-mail: agokhanyazici@hotmail.com
}

\begin{abstract}
Corrective actions are a branch of applied science and include the identification, education, prevention, correction of wrong habits of body and motor abnormalities. The purpose of this study was to assess the effectiveness of eight-week corrective exercises on boy students with kyphosis and lordosis. 40 boy students were randomly divided into two groups with 20 subjects in each group including experimental group and control group. The experimental groups performed the corrective exercises for eight weeks with three sessions a week. Pre and post measures of kyphosis and lordosis curve were obtained using a spinal mouse. Measuring of variables was performed before (pre-test) and after (post-test) the protocol. Eight weeks corrective exercise period can be resulted in the reduction of kyphosis angle and lordosis angle boy student. In general, implementation of corrective exercise in patients with kyphosis and lordosis was a successful plan.
\end{abstract}

Keywords: Boy students, corrective exercises, lumbar lordosis, spinal mouse, thoracic kyphosis.

\section{INTRODUCTION}

The spine as the linchpin of the body is a complex structure consisting of vertebrae, discs, muscles and many ligaments (26). This weakness of spinal column extensor muscles can cause to static, dynamic and stature unbalance in persons that called faulty posture (2). Sagittal spinal alignment is found to be changing as a child grows. There is a statistically significant difference among different age groups, especially at cervicothoracic, thoracolumbar, and lumbosacral junctions. The position of the sacrum (inclination and translation), and spatial orientation, as well as the global magnitude of thoracic kyphosis, and lumbar lordosis changes with growth. These findings should be taken into consideration for the young patients who require spinal instrumentation (5). Fanuchi et al. (8) confirmed Espinoza-Navarro et al. (7) who reported an implementation of exercise program decline rates of postural abnormalities in 4year-old children and regular involvement in specific exercise programs during childhood could promote optimal spinal alignment and tissue load during the growth spurt. Hasanvand et al. (11) reported, corrective exercises can begin with the onset of puberty. Puberty is periods of life when posture undergoes many adjustments and adaptations (23), due to changes in the body, vertebral anatomical dimensions, body height, and hormonal status. Postural changes cause deformity in children and adolescence's posture, if improvement is not done, then the structural changes occur (14).

Physiological disorders caused by unfavorable physical status are serious. Increasing back curve of a thoracic area that recognized as kyphosis has the unfavorable result of the respiratory system by the shortness and the inflexibility of chest muscles and also the weakness of expiratory muscles. Because shortening weakness in chest muscles of aspiration cause to decreasing ribcage volume, then decreasing lung volume (24). The mechanism of kyphosis is presumed to occur through anterior thoracic compression fractures and the subsequent formation of a compensatory fat pad (6). Kyphosis is not only associated with relatively altered vertebral body shape (anterior wedging), but also with reduced bone density and fitness, as well as decreased muscle strength, and is associated with reduced survival (20). It is concluded that similar fitness and corrective exercises are possibly recommendable for mentally retarded adolescents (19). We can suggest the performance of both corrective exercises in land and water for kyphotic persons (2). The kyphosis angle 
has been correlated with back extension strength, which is an important predictor of quality of life among postmenopausal women with osteoporosis (21). Our previous study (12) showed improved kyphosis, strength, and physical performance after a 12-week multidimensional exercise program.

One of the important abnormalities of this area is the increased lumbar lordosis (22). Maintenance of normal lumbar lordosis is important in the treatment of spinal disorders (25). Mackenzie believes that failure to correct these abnormalities until high school will lead to the postural changes like pains in the musculoskeletal system, joint deformation, muscular fatigue, and biomechanical imbalances (16). Hence, correcting the lifestyle which is effective on the emergence of lumbar lordosis should be taken into account (26). Lumbar lordosis is defined as the curvature assumed by the intact lumbar spine to compensate for the inclination of the sacrum, restore an upward orientation and consequently avoid forward inclination (30). Corrective exercises had the significant effect on increased lumbar lordosis especially after puberty (27).

Kyphosis is the excessive curvature of the spine in the sagittal plane. The normal back has $20^{\circ}$ to $45^{\circ}$ of curvature in the upper back, and anything in excess of $45^{\circ}$ is called kyphosis. Lordosis or hyperlordosis is excessive curving of the lower spine and is often associated with scoliosis or kyphosis. It can be exaggerated by poor posture. Abnormal curvature of the spine can result from disease of the vertebral column, including trauma or imbalance of the neuromuscular system. It may be congenital. It can be produced by legs of different lengths.

In adults, kyphosis is often related to osteoporosis but in children, it can be due to injury, a tumor on the spine, or a genetic disorder, such as Hunter's syndrome or spina bifida. Hence, the purpose of this study was to assess the effectiveness of eight-week corrective exercises on boy students with kyphosis and lordosis.

\section{MATERIALS \& METHODS}

The 40 boy students with kyphosis and lordosis with mean and standard deviation, the age profile (17.24 \pm 2.84 yr.), weight $(61.29 \pm 3.69 \mathrm{~kg})$ and height $(168.61 \pm 4.72 \mathrm{~cm})$ participated in this study. The subjects were recruited from a high school. They were randomly divided into experimental (20 cases) and control (20 cases) groups. Each subject was questioned about them passed medical history and present health status. The subjects received a stipend to cover their travel expenses and time. Prior to the study, procedures and guidelines were presented orally and in written form. Subjects agreeing to participate signed an institutionally approved consent form.

Anthropometric characteristics including height and weight were measured and recorded. Measuring of variables was performed before (pre-test) and after (post-test) the protocol. The experimental group participated in corrective exercises program for eight weeks, three sessions per week and 60 minutes per session, while the control group did not participate in any corrective exercises and not to participate a regular exercise program or a sport, during the study. The Control group was also able to do the physical activity. After completion of initial measurements for the evaluation of the curvature of the kyphosis and lordosis, the experimental group participation in corrective exercises program. Corrective exercise was performed by the subjects under the supervision of the athletic trainer. On the day after the end of the corrective exercises program, the evaluation of the curvature of the kyphosis and lordosis were repeated. Evaluation of the curvature of the kyphosis and lordosis was the spinal mouse.

Spinal Mouse is a device that, combined with a computer program, assesses the curvatures of the vertebral column without applying harmful radiation. The Spinal Mouse device includes two rollers included on a mobile support that allows spinous contour tracking. This shape is recorded by three sensors. The Spinal Mouse results, emphasizing values such as hypo or hyper mobile vertebral joints or deviations from reference values.

Corrective exercises program: 1 . Warm up 10 min, 2. Stretching10 min (Improve of Flexibility and range of motion), 3. Strengthening $30 \mathrm{~min}$ (Increased of strength and endurance in the large muscle groups), 4. Cool down $10 \mathrm{~min}$.

Combined program of stretching and strengthening includes: PNF stretching (chest stretch, groin stretch, hamstring and gluteal stretch), strengthening the abdominal muscles (Stomach crunch with legs raised, Side plank, Plank, Stomach crunch), hip flexor and extensor exercises (Bridging, Adductor Squeeze, Hip Abduction Sideling, Hip Abduction Standing, Hip Flexion), Williams exercises, strengthening of erector spine muscles.

All data were analyzed using SPSS version 19. The data were tested for normal distribution with the Shapiro-Wilk test. The paired T-test was used to 
compare the differences between the pre and posttest in both groups. Significances were set at the $\mathrm{P}<0.05$ level.

\section{RESULTS}

Mean and SD values of age, height and weight of two groups are shown in Table 1.

Table 1. Characteristics of subjects (mean \pm SD).

\begin{tabular}{lcccc}
\hline Group & $\mathrm{N}$ & $\begin{array}{c}\text { Age } \\
(\mathrm{yr})\end{array}$ & $\begin{array}{c}\text { Height } \\
(\mathrm{cm})\end{array}$ & $\begin{array}{c}\text { Weight } \\
(\mathrm{kg})\end{array}$ \\
\hline Experimental & 20 & $16.84 \pm 1.84$ & $168.07 \pm 2.21$ & $61.74 \pm 0.69$ \\
Control & 20 & $17.53 \pm 2.07$ & $169.01 \pm 2.38$ & $61.02 \pm 1.11$ \\
\hline
\end{tabular}

Table 2 shows for normal distribution with the Shapiro-Wilk test before performed exercise in both groups. The result of analysis indicated that there was no significant difference in both variables in experimental and control groups.

Table 2. The result of analysis for normal distribution with Shapiro-Wilk test.

\begin{tabular}{lll} 
Curvature & Group & $\mathrm{P}$ \\
\hline Kyphosis & Experimental & 0.59 \\
& Control & 0.57 \\
Lordosis & Experimental & 0.64 \\
& Control & 0.54 \\
\hline
\end{tabular}

Table 3 compares for kyphosis curvature in of subjects in the pre and post-test in two groups. The result of analysis indicated that there was no significant difference in pre and post-test in control group. Significant difference found between pre and post-test in experimental groups in kyphosis curvature $(\mathrm{P}<0.05)$.

Table 4 presents compares of pre and post-test for lordosiscurvature in both groups. Significant difference found between pre and post-test in experimental group inlordosiscurvature $(\mathrm{P}<0 / 05)$ and between pre and post-test of subjects in control group there was no significant difference in this variable $(\mathrm{P}<0 / 05)$

\section{DISCUSSION}

The purpose of this study was to assess the effectiveness of eight-week corrective exercises on boy students with kyphosis and lordosis. The research shows there is an important decrease in kyphosis and lordosis angle after a particular corrective exercise in experimental group. Our results showed that curvature of kyphosis and lordosis can be improved. Findings revealed that the program had therapeutic effects and decreased thoracic kyphosis and lumbar lordosis (19). Corrective exercises decreased periodical backache and increased mental health and satisfaction of patients (9). Researchers believed strengthening exercises is a part of corrective exercise that can enhance the muscular strength of children and adolescents beyond that which is normally due to growth and development (27). Upon 8 weeks corrective exercise, the amount of the back curved decreased significantly and there was a significant increase in abdominal muscle strength and endurance, and hamstring muscle flexibility (1)

Table 3. Paired T-test for kyphosis curvature of subjects in the pre-test and post-test in two groups.

\begin{tabular}{llccccc}
\hline Curvature & Group & Pre test & Post test & $\mathrm{df}$ & $\mathrm{t}$ & $\mathrm{p}$ \\
\hline Kyphosis & Experimental & $46.19 \pm 3.29$ & $42.38 \pm 1.14$ & 19 & 6.39 & $0.000^{*}$ \\
& Control & $45.71 \pm 2.94$ & $45.31 \pm 3.02$ & 19 & 1.04 & 0.185 \\
\hline
\end{tabular}

${ }^{*} \mathrm{p}<0.05$.

Table 4. Paired T-test for lordosiscurvature of subjects in the pre-test and post-test in two groups.

\begin{tabular}{lllcccc}
\hline Curvature & Group & Pre test & Post test & df & $t$ & $p$ \\
\hline Lordosis & Experimental & $48.23 \pm 1.74$ & $43.56 \pm 0.97$ & 19 & 7.51 & $0.000^{*}$ \\
& Control & $48.51 \pm 2.18$ & $49.63 \pm 1.85$ & 19 & 1.17 & 0.117 \\
\hline$* \mathrm{p}<0.05$ & & & & &
\end{tabular}


The results of the present research are consistent with previous findings indicating an improvement of angle of kyphosis after corrective exercises in land and water (2). Choi (4) and Lynn (15) show through corrective exercises to increase power of back extensor muscles, the kyphosis would decrease, pain relief and physical function $(4,15)$. Hyper-kyphosis (a thoracic curvature of $>40-45^{\circ}$ ) is one of the most common human postural abnormalities and has been identified as an etiological factor of, or significant cause of, impairment in upper quadrant pathologies $(10,13)$. The incidence of hyper-kyphosis has been shown to range from $15.3 \%$ in 11 year-old children to $38 \%$ in $20-50$ year-old adults and 35\% in 20-64 yearold adults depending on the dataset (28). This abnormality is often managed by manual therapists in many disciplines using a variety of techniques, including exercise prescription (28). A 7 week corrective exercise period can be resulted in reduction of kyphosis angle in hyper-kyphotic male students. But by stopping the exercises completely, the kyphosis angle may increase again (29). Regular and correct exercises may lead to increase muscular power and decrease lordosis (17).

Posture is the alignment and maintenance of body segments in certain positions such as standing, walking, lying or sitting, and is the most important factors affecting physical and mental status of individuals through their lives (31). Bad posture may be attributed to muscle and emotional issues, which could generate positional or structural deviations if the individual remains in inappropriate positions for a long time (18). Hyperkyphosis or increase in thoracic curve greater than normal range is one of prevalent spinal disorders (3). Biomechanical data suggest that an increase in the thoracic kyphosis may be associated with significantly higher spinal loads and trunk muscle force in upright stance and this might accelerate degenerative process which in turn leads to further spinal dysfunction and pain (3). Lordosis is the inward curvature of spine. In fact, it is an increased forward curve in the lumber region. It creates problem in standing and walking. Generally imbalanced diet, improper environment improper development of muscles, obesity and diseases affecting vertebrae and spinal muscles are such causes which result in lordosis. In addition to these causes, not performing exercises and taking excessive food are also major causes of lordosis. Abnormal spinal curves can be the result of many different causes. Some children or adolescents may have a nerve or muscle disease (neuromuscular), injury or other illness that may have attributed to their spinal abnormality.

In conclusion; findings revealed that the program had therapeutic effects and decreased thoracic kyphosis and lumbar lordosis. In general, implementation of corrective exercise in boy students with kyphosis and lordosis was a successful plan.

\section{ACKNOWLEDGEMENTS}

The authors of this article would like to express their appreciation to the dear subjects who helped us collect this data by their participation in the study.

\section{REFERENCES}

1. Abbaszadeh A, Sahebzamani M, Seifadini MA, Samsampour D. Effect of an 8-week corrective exercise on hyperlordosis girl students. Hormozgan Medical Journal, 2012; 16(5): 377-386.

2. Azizi A, Mahdavinejad R, Allah Taheri Tizabi A, BabaiMazreno A, SalmaniNodoushan I, Reza Behdoust M. (2012). The effect of 8 weeks specific corrective exercise in water and land on angle of kyphosis and some pulmonary indices in kyphotic boy students. Sport Science, 2012; 2: 62-65.

3. Briggs AM, Wrigley TV, Tully EA, Adams PE, Greig AM, Bennell KL. (2007). Radiographic measures of thoracic kyphosis in osteoporosis: Cobb and vertebral centroid angles. Skeletal Radiology, 2007; 36(8): 761-767.

4. Choi EH, Hur JK, Yang JI, Park DS. Poster 98: The effect of thoracic exercise program on thoracic pain, kyphosis, and spinal Mobility. Archives of Physical Medicine and Rehabilitation, 2005; 86(9): e23.

5. Cil A, Yazici M, Uzumcugil A, Kandemir U, Alanay A, Alanay Y, Acaroglu RE, Surat A. The evolution of sagittal segmental alignment of the spine during childhood. Spine, 2005; 30(1): 93100.

6. Culter WB, Friedman E, Genovese SE. (1993). Prevalence of kyphosis in healthy sample of pre and postmenopausal women. AM J Phys Med Rehabil, 1993; 72(4): 219-225.

7. Espinoza-Navarro O, Valle S, Berrios G, Horta J, Rodríguez H, Rodríguez M. Prevalence of postural alterations and effects of a program to improve the posture in children from AricaChile. Int J Morphol, 2009; 27(1): 25-30.

8. Fanucchi GL. Specific exercises as a secondary preventative intervention programme for low back pain in 12-13 year old children. Johannesburg: University of the Witwatersrand, 2007.

9. Ghorbani L, Ghasemi G. Effects of eight weeks corrective exercises on lumbar lordosis. Journal of Research in Rehabilitation Sciences. 2008; 3(2): 59-71.

10. Granito RN, Aveiro MC, Renno AC, Oishi J, Driusso P. Comparison of thoracic kyphosis degree, trunk muscle strength and joint position sense among healthy and osteoporotic elderly women: A cross-sectional preliminary study. Arch Gerontology and Geriatrics, 2012; 54: 199-202.

11. Hasanvand B, Bahrami F, Darvishi A, Karimi K. Effect of corrective exercise on muscle-skeletal abnormality of Khoram Abad city school girl. Lorestan Med J, 2011; 1(13): 79-85. 
12. Katzman WB, Sellmeyer DE, Stewart AL, Wanek L, Hamel KA. Changes in flexed posture, musculoskeletal impairments, and physical performance after group exercise in communitydwelling older women. Arch Phys Med Rehabil, 2007; 88: 192 199.

13. Katzman WB, Wanek L, Shepherd JA, Sellmeyer DE. Agerelated hyperkyphosis: its causes, consequences, and management. J Orthop Sports Phys Ther. 2010; 40(6): 352.

14. Kratenova J, Ejglicova KZ, Maly M, Filipova V. Prevalence and risk factors of poor posture in school children in the Czech Republic. J Sch Health, 2007; 77(3): 131-137.

15. Lynn H. Exercise may ease kyphosis effect. Improving posture and muscle strength reduce curvature of spin. Journal of American College of Rheumatology, 2001.

16. Mackenzie WG, Sampath JS, Kruse RW, Sheir-Neiss GJ Backpacks in children. Clinical orthopaedics and related research, 2003; 409: 78-84.

17. MajidiSiahtan S, Behbudi L. (2015). The impact of 8-week selected Pilates exercises on lordosis correction and BMI in female teens aged 15-18. Biological Forum - An International Journal, 2015; 7(1): 1267-1271.

18. Malepe MM, Goon DT, Anyanwu FC Amusa LO. The relationship between postural deviations and body mass index among university students. Biomedical Research. 2015; 26(3): 437-442.

19. Mashhadi M, Gholamali G, Zolaktaf V. Effect of combined training exercises on the thoracic kyphosis and lumbar lordosis of mentally retarded adolescents. Journal of Research in Rehabilitation Sciences, 2012; 8(1): 192-201.

20. Milne JS, Williamson J. A longitudinal study of kyphosis in older people. Age Aging, 1983; 12: 225-233.

21. Miyakoshi N, Hongo M, Maekawa S, Ishikawa $Y$, Shimada $Y$, Itoi E. Back extensor strength and lumbar spinal mobility are predictors of quality of life in patients with postmenopausal osteoporosis. Osteoporos Int, 2007; 18: 1397-1403.

22. Nazarian AB, Daneshjoo A, Ghorbani L, Ghaedi H. The prevalence of lordotic and kyphotic deformities among different age groups. Research in Rehabilitation Sciences. 2010; 5(1): 24-32.

23. Penha PJ, Casarotto RA, Sacco ICN, Marques AP, João SMA Qualitative postural analysis among boys and girls of seven to ten years of age. Rev Bras Fisioter. 2008; 12(5): 386-918.

24. Rajabi R, Seidi F, Mohamadi F. Which method is accurate when using the flexible ruler to measure the lumbar curvature angle? Deep pint or mid-point of arch? World Applied Sciences Journal, 2008; 4(6): 849-852.

25. Gardocki RJ, Watkinsm RG, Williams LA. Measurements of lumbopelvic lordosis using the pelvic radius technique as it correlate with sagittal spinal balance and sacral translation. The Spine Journal, 2002; 2: 421-429.

26. Rezvankhah N, Alizadeh MH, Kordi MR. The effect of four months of detraining following eight months of corrective exercises on lumbar lordosis of schoolgirls. Annals of Applied Sport Science, 2013; 1(2): 19-24.

27. Rezvankhah N, Alizadeh MH, Kordi MR. The effect of puberty on effectiveness of corrective exercise on school girls. Zahedan J Res Med Sci, 2014; 16(6): 83-84.

28. Seidi F, Rajabi R, Ebrahimi I, Alizadeh MH, Minoonejad H. The efficiency of corrective exercise interventions on thoracic hyper-kyphosis angle. Journal of Back \& Musculoskeletal Rehabilitation, 2014; 27: 7-16.

29. Shavandi N, Shahrjerdi S, Heidarpor R, Sheikh-Hoseini R. The effect of 7 weeks corrective exercise on thoracic kyphosis in hyper-kyphotic students. Journal of Shahrekord University of Medical Sciences, 2011; 13(4): 42-50.

30. Skaf GS, Ayoub CM, Domloj NT, Turbay MJ, El-Zein C, Hourani MH. Effect of age and lordotic angle on the level of lumbar disc herniation. Advances in Orthopedics, 2011; ID: 950576. doi:10.4061/2011/950576

31. Zagyapan R, Iyem C, Kurkcuoglu A, Pelin C, Tekindal MA The relationship between balance, muscles, and anthropomorphic features in young adults. Ant Res Int, 2012; Article ID: $146063,1-6$. 